\title{
Study of Ophthalmic Causes of Headache in Tertiary Health Care Centre in Central India
}

\author{
Author \\ Khalid Khan \\ Assistant Professor, Mahaveer Institute of Medical Sciences \& Research Centre, Bhopal \\ Corresponding Author \\ Dr Khalid Khan \\ 110, Royal apartment, Kohe Fiza, Bhopal, MP India \\ Email-drkhalid.khan@yahoo.co.in
}

\begin{abstract}
Introduction: headache is a common complain of patients in eye OPD. Headache may be caused by various ophthalmic and non ophthalmic causes. Detail history taking and comprehensive clinical examination is required to make proper diagnosis of headache.

Objective: The aim of the study is to clinically evaluate the ophthalmic cause of headache in patients attending eye OPD with chief complain of headache.

Material and Method: A prospective study of 568 cases of headache attending eye OPD was done. Ophthalmological examination including refraction under appropriate

cycloplegia, strabismus evaluation, anterior segment examination on Slit lamp, direct and indirect ophthalmoscopy, intraocular pressure measurement and examination of adnexa was done. cases in which no ophthalmological cause of headache was found were refer to other departments as suggested by history and associated complain.

Results: Out of 568 cases, in 177 cases ophthalmic causes of headache were found. Headache incidence were more in females (59.3\%) cases than males(40.7\%). headache was found to be more prevalent in 10-30 years age group (54\%).refractive erros (59.8\%) was most common cause of ophthalmic headache followed by presbyopia (11.8\%), muscular imbalance (7.9\%),computer vision syndrome(6.25\%), glaucoma(3.3\%)lid inflammation (2.8\%), uveitis (2.8\%) and keratitis (1.6\%).Astigmatism(44.3\%) and Hypermetropia (33.0\%) were most common refrective errors causing headache.

Conclusion: Most common causes of ophthalmic headache are refractive errors, presbyopia, muscle imbalance, coputer vision syndrome and anterior segment pathology.

Keywords: Headache, refractive error, presbyopia, computer vision syndrome, glaucaoma, uveitis.
\end{abstract}

\section{Introduction}

Headache is quite a common symptom. Pain located above orbitomeatal line is termed as headache. Although it is a common complaint but often misdiagnosed and inadequately treated. Differential diagnosis of headache is probably one of the longest in all of the diseases. ${ }^{1}$ headaches are broadly classified as primary or secondary. Primary headaches are benign, recurrent headaches not caused by underlying disease or structural problems. On the other hand Secondary headaches are caused by an underlying disease 


\section{JMSCR Vol||06||Issue ||04||Page 1078-1081||A pril}

like an infection, head injury, vascular disorder or tumors. Brain itself is not sensitive to pain because it lacks pain receptors however pain can be sensed by several areas of head and neck as they have pain receptors. Many primary headache disorders may have ophthalmic features and secondary causes of headache frequently involve the visual system. Due to close link between eye and headache, ophthalmologists are usually the first physician to evaluate patients with headache. There are many ophthalmological causes of headaches like refractive errors, computer vision syndrome, convergence insufficiency, uveitis, keratitis, glaucoma, lid and lachrymal sac inflammations etc.

The objective of the present study is to evaluate ophthalmic causes of headache in patients attending eye OPD in tertiary health care centre in central India.

\section{Material and Method}

This prospective study carried out in the Department of Ophthalmology, Peoples College of Medical Sciences and Research Centre, Bhopal. Study was conducted on 568 patients attending ophthalmic OPD with chief complain of headache from February 2012 to April 2014.

A detailed clinical history was taken with emphasis on onset, duration, location, intensity, character and exaggerating factors of headache. A comprehensive ophthalmic examination was done. Visual acuity of each eye for distance and near was recorded. Slit lamp examination was done to rule out anterior segment pathology. All the patients were then subjected to thorough dark room investigations. Cover test for distance and for near were conducted to rule out latent squint. Ocular movements were tested uniocularly and binocularly.

Retinoscopy was done under appropriate cycloplegia. A Post Mydriatic Test was done after 3 days if retinoscopy had been done under homatropine and after 2 weeks if it had been done under atropine. Orthoptic evaluation included measurement of the near point of convergence and power of accommodation. Maddox rod test and Maddox Wing test were used to detect hetrophoria. Examination on synoptophore was done. Fundus was examined by both direct and indirect ophthalmoscopy.

Patients in which no ophthalmic cause of headache was found were referred to other departments like medical, paediatrics, ENT, neurology, or psychiatry as suggested by history and investigation.

\section{Result}

In 568 cases of headache, 337 were females and 231were males.

Table 1 Sex distribution of cases

\begin{tabular}{|l|c|c|c|c|}
\hline Age group & \multicolumn{2}{|c|}{ males } & \multicolumn{2}{c|}{ females } \\
\hline $10-30$ & 129 & $22.7 \%$ & 178 & $31.3 \%$ \\
\hline $30-50$ & 67 & $11.8 \%$ & 102 & $17.9 \%$ \\
\hline $50-70$ & 35 & $6.1 \%$ & 57 & $10.0 \%$ \\
\hline Total & $\mathbf{2 3 1}$ & $\mathbf{4 0 . 7 \%}$ & $\mathbf{3 3 7}$ & $\mathbf{5 9 . 3 \%}$ \\
\hline
\end{tabular}

Table 2 Age distribution of cases

\begin{tabular}{|l|c|c|}
\hline Age group & Number of cases & percentage \\
\hline $10-30$ & 307 & $54.0 \%$ \\
\hline $30-50$ & 169 & $29.8 \%$ \\
\hline $50-70$ & 92 & $16.2 \%$ \\
\hline Total & $\mathbf{5 6 8}$ & $\mathbf{1 0 0 \%}$ \\
\hline
\end{tabular}

Table 3 Ophthalmic causes of headaches

\begin{tabular}{|l|c|c|}
\hline Cause of headache & Number of cases & percentage \\
\hline Ophthalmic & 177 & $31.1 \%$ \\
\hline Non ophthalmic & 391 & $68.9 \%$ \\
\hline Total & & \\
\hline
\end{tabular}

Table 4 Distribution of ophthalmic causes (177 cases)

\begin{tabular}{|l|c|c|}
\hline Ophthalmic cause & $\begin{array}{c}\text { Number of } \\
\text { cases }\end{array}$ & Percentage \\
\hline Refractive error & 106 & $59.8 \%$ \\
\hline Presbyopia & 21 & $11.8 \%$ \\
\hline Muscular imbalance & 14 & $7.9 \%$ \\
\hline Computer Vision syndrome & 11 & $6.2 \%$ \\
\hline Sty & 5 & $2.8 \% \%$ \\
\hline Uveitis & 5 & $2.8 \%$ \\
\hline Corneal ulcer & 3 & $1.6 \%$ \\
\hline POAG & 3 & $1.6 \%$ \\
\hline Acute congestive glaucoma & 2 & $1.1 \%$ \\
\hline Acute dacryocystitis & 2 & $1.1 \%$ \\
\hline Lens induced glaucoma & 1 & $0.56 \%$ \\
\hline Bullous keratopathy & 1 & $0.56 \%$ \\
\hline Herpes zoster ophthalmicus & 1 & $0.56 \%$ \\
\hline Pappiloedma & 1 & $0.56 \%$ \\
\hline Orbital cellulitis & 1 & $0.56 \%$ \\
\hline Total & $\mathbf{1 7 7}$ & $\mathbf{1 0 0 \%}$ \\
\hline
\end{tabular}


Table 5 Distribution of refractive errors in headache cases (106 cases)

\begin{tabular}{|l|c|c|}
\hline $\begin{array}{l}\text { Type of refractive } \\
\text { errors }\end{array}$ & $\begin{array}{c}\text { Number of } \\
\text { cases }\end{array}$ & percentage \\
\hline Astigmatism & 47 & $44.3 \%$ \\
\hline Hypermetropia & 35 & $33.0 \%$ \\
\hline Myopia & 15 & $14.1 \%$ \\
\hline mixed & 9 & $8.4 \%$ \\
\hline Total & $\mathbf{1 0 6}$ & $\mathbf{1 0 0 \%}$ \\
\hline
\end{tabular}

\section{Discussion}

\section{Sex incidence}

In our study out of 568 cases of headaches attending ophthalmic OPD, 337 cases were females and 231 cases were males. In our study $59.3 \%$ cases were females and $41.7 \%$ cases were males. Our findings are consistent with finding of Dhir $^{2}$ and Lanchner ${ }^{3}$ who reported incidence of headaches in females $57 \%$ and $58.3 \%$ respectively. Higher incidence of headache in females were also reported by Marasini et $\mathrm{al}^{4}$.this may be contributed by psychological stress in females particularly working females having dual responsibility of family and job.

\section{Age incidence}

In our study highest incidence of headache were seen in 10-30 age group.54\% cases of headaches were reported in this age group. Similar age predisposition has been reported by previous studies by Ahmed and Zuberi ${ }^{5}$.the higher incidence in this age group may be contributed by students under the pressure of study and young adults under target achievement pressure and insecurity of jobs. Emotional instability in personal relations may also be a contributory factor .Excessive use of modern gazettes and social media may also be contributing to headache in this age group.

\section{Ophthalmic causes}

In our study of 568 cases 177 cases were having ophthalmic causes of headache. Out of all the patients attending eye OPD for headache complain $31.1 \%$ of cases could be related to ophthalmic causes. J Kumar et $a^{6}$ reported up to $45 \%$ cases having a ophthalmic cause of headache among all patients seeking consultations in eye OPD for headache.

\section{Distribution of ophthalmic causes of headache}

In our study most common ophthalmic cause of headache was uncorrected or improperly corrected refractive errors $(58.8 \%)$ followed by presbyopia (11.8\%)and muscular imbalance (7.9\%). Similar finding were also reported by Cogan ${ }^{7}$.In our study $6.2 \%$ cases of headache were associated with computer vision syndrome..

\section{Types of Refractive Errors in headache cases}

In present study most common refractive error in headache patients was astigmatism (44.3\%) followed by hypermetropia (33\%). Marasini et $\mathrm{al}^{4}$ observed astigmatism in $63.6 \%$ cases and hypermetropia in $27.7 \%$ of cases. Only $14.1 \%$ cases of refractive error were myopic.

Low incidence of headache among myopic cases may be contributed by less use of accommodation by myopic patients.

\section{Muscular imbalance in headache cases}

In present study $7.9 \%$ cases of ophthalmic headaches were found to have muscular imbalance. Out of this $58 \%$ cases were having convergence insufficiency followed by $24 \%$ exophoria cases and $18 \%$ esophoria cases. Similar incidence was reported by Gupta et $\mathrm{al}^{8}$.

\section{Computer Vision Syndrome}

In our study $6.2 \%$ cases of ophthalmic headache were associated with computer vision syndrome. Marasini et al ${ }^{4}$ observed $13 \%$ of cases of compuer vision syndrome and DAum K M et al ${ }^{9}$ repoerted 9\% cases of ophthalmic headaches related to computer vision syndrome. headaches in computer vision syndrome is attributed to dry eye and spasm of accommodation.

\section{Anterior segment causes of headache}

In our study glaucoma, uveitis and keratitis were found to be the most common anterior segment causes of headaches. Glaucoma was found in $42 \%$ 
cases, uveitis in $35 \%$ cases and keratitis in $21 \%$ cases. No comparable data was found in previous studies.

\section{Lid and adnexa causes in headache}

Inflammation of lid and lachrymal sac was also observed as cause of headache in our study but no comparable data was found.

\section{Non ophthalmic causes}

In our study of 568 cases in 391 (68.9\%) cases no ophthalmic cause of headache was found and these cases were referred to other departments. As per the feedback received from other department the most common cause of headache in these cases were primary headache followed by hypertension, ENT and neurological problems.

\section{Conclusion}

Headache is a common symptom which brings patients to eye OPD.A thorough ophthalmological examination is required to detect ophthalmic causes in these patients. As majority of headache patients attending eye OPD are not having ophthalmological causes of headache, so interdepartmental coordination is very important in diagnosis and management of headache cases. An ophthalmologist has important role to play in diagnosis of cause and management of headache.

\section{References}

1. Martin TJ, Soyka D. Ocular causes of headache. In: The Headaches, Olesen J, Tfelt-Hansen P, Welch KMA (Eds). New York: Raven Press, 1993. p. 748.

2. Dhir BK. Convergence insufficiency. Indian J Ophthalmol 1961;9:33-5.

3. Lanchner AJ. Headache in ophthalmic practice. Neurology,1952;2:471-6.

4. Marasini S, Khadka J, Sthapit PRK, Sharma R, Prasad B. Ocularmorbidity on headache ruled out of systemic causesaprevalence study carried out at a community based hospital inNepal. Nepal J Optom 2012;5:68-74.
5. Ahmed SH, Zuberi H. Depression anxiety and headache. J Pak Med Assoc 1981;31:276-9.

6. J kumar et al Headache: An Out Patients Clinic Approach (Ophthalmological View. OSR Journal of Dental and Medical Sciences (IOSR-JDMS) e-ISSN: 22790853, p-ISSN: 2279-0861.Volume 16, Issue 11

7. Cogan DG. Popular misconceptions pertaining to ophthalmology. New Engl J Med 1941;224:462-6.

8. Gupta A, Kailwoo SK, Vijayawali. Convergence insufficiency inpatients visiting eye OPD with headache. JK Science 2008;10:135-6.

9. Daum K.M., Good G.,Tijerina L. Symptoms in video display terminal operaters and the presence of small refractive errors.J Am Optom Assoc.1988;59:691-697. 